$\mathbb{T}$ periodica polytechnica

Civil Engineering

$57 / 1(2013) 3944$

doi: 10.3311/PPci.2140

http://periodicapolytechnica.org/ci

Creative Commons Attribution (1)

RESEARCH ARTICLE

\section{Correlation of undrained shear strength and CPT resistance}

\author{
Zsolt Rémai
}

Received 2012-05-16, accepted 2012-08-25

\begin{abstract}
The correlation of CPT resistance and undrained shear strength of soft Holocene clays is discussed in this paper. This soil type, covering significant part of Hungary is frequently involved in different geotechnical engineering problems such as building of highway embankments. Soil samples of eight different sites have been studied, samples were taken at each site and cone penetration tests were performed. The samples were tested by means of unconfined compression and consolidatedundrained triaxial compression tests. The correlation of the determined undrained shear strength and the experienced CPT results was evaluated and the empirical cone factors $\left(N_{k}, N_{k t}, N_{k e}\right.$, $N_{\Delta u}$ ) were determined for each tests. The back-calculated cone factors have been compared with the values suggested by earlier works in this field. The possible correlations between cone factors and different soil properties (such as index of plasticity, pore pressure coefficient etc.) are also discussed in the paper and recommendations are given for estimation of undrained shear strength of Holocene clays.
\end{abstract}

\section{Keywords}

undrained shear strength $\cdot \mathrm{CPTu} \cdot$ empirical correlation

\section{Zsolt Rémai}

Budapest University of Technology and Economics, Department of Geotechnics, H-1111 Budapest, Múegyetem rkp. 3., Hungary

e-mail: remai@vnet.hu

\section{Introduction}

Building on soft cohesive soils involves many geotechnical issues. The high compressibility of the soils causes significant settlements which generally develop slowly. As the required construction times are reducing, long term deformation of soils is rarely affordable, therefore different soil improvement techniques are generally used to decrease and accelerate the settlements. Another important issue is the limited strength and bearing capacity of soft soils. The shear strength of soils determines the maximum allowable load which can be applied on it (e.g. maximum footing pressure, embankment height etc.). In the case of cohesive soils the undrained loading condition is the least favorable, so it is the undrained shear strength that governs the bearing capacity. Undrained shear strength $\left(s_{u}\right)$ is a commonly accepted and used soil parameter and there are numerous ways to obtain it. Nevertheless it is not a single soil parameter. The measured undrained shear strength depends on testing method (failure mode), strain rate, stress path and many other factors (Mayne et al., 2009) [12]. Therefore it is important to clearly define which undrained shear the given data refers to.

This paper focuses on correlation of CPT results and undrained shear strength values determined by means of consolidated-undrained triaxial and unconfined compression tests. There are numerous methods available to estimate undrained shear strength of clays of different types, but there is no information about their reliability in case of soft Holocene clays located in the Carpathian Basin. A reliable correlation of the test results could provide more detailed information on the shear strength of such soils at many sites by having CPTu measurements at every two centimeters. The number of data could also enable a statistical analysis of the undrained strength values, thereby could also provide information on the uncertainty of the strength parameter which is essential for failure probability assessment (Nagy, 2008) [13].

Data from 8 different sites are summarized and evaluated in this paper. At each location the upper 5-10 m thick layer was formed by soft, Holocene clays, having a CPT tip resistance $\left(q_{c}\right)$ value less than $2 \mathrm{MPa}$. 


\section{Existing correlations, performed tests}

Cone penetration testing have been used for a long time in soil exploration, and determining pile bearing capacity (Mahler, 2003) [10] and the undrained shear strength of soft soils is one of the earliest applications.

There are many theoretical solutions based on different considerations such as bearing capacity theory (Terzaghi, 1943 [17]; de Beer, 1977 [2]), cavity expansion theory (Skempton, 1951 [15]; Vesic, 1975 [18]), analytical and numerical approaches (Ladanyi, 1967) [8] or strain path theory (Teh, 1987) [16]. A detailed summary of these methods is given in Lunne et al. (1997) [9]. The undrained shear strength can be derived in a very similar way in each of the theoretical proposals, the general formula can be written as:

$$
s_{u}=\left(q_{c}-\sigma_{0}\right) / N_{c}
$$

where

$s_{u}$ is the undrained shear strength,

$N_{c}$ is the theoretical cone factor,

$\sigma_{0}$ is the total horizontal, vertical or mean stress (depending on the theory considered).

The derived theoretical expressions have pointed out that a reliable correlation can be found between the undrained shear strength and CPT tip resistance, if the in situ stress state is taken into consideration. These expressions became the theoretical basis of later empirical or semi-empirical correlations which are commonly defined by the same equation form, but in order to differentiate distinguish them from the theoretical solutions the empirical cone factor is denoted by $N_{k}$.

$$
s_{u}=\left(q_{c}-\sigma_{v 0}\right) / N_{k}
$$

where

$N_{k}$ is the empirical cone factor,

$\sigma_{v 0}$ is the total overburden stress.

Many analyses have been conducted to obtain typical cone factor values for different soil types. Lunne and Kleven (1981)[19] have found that $N_{k}$ varied between 11 and 19 (having an average value of 15) for normally consolidated, Scandinavian marine clays with field vane test as a reference test. Jörss (1998) [7] recommends the use of $N_{k}=20$ for marine clays and $N_{k}=15$ for boulder clays. Gebreselassie (2003) [5] has summarized the German experiences and has proposed different values ranging from 7.6 to 28.4 for different soil types. Summarizing results of three test sites in Malaysia, Chen (2001) [3] experienced cone factor values varying between 5 and 12 .

The wide range of cone factor values implies that care must be taken when using such empirical correlation. They can be used only if there are comparative experiences on similar soil types and geological conditions. The goal of this study is to evaluate the test results of Holocene clays in the Charpatian Basin, thereby to provide a recommendation for choosing appropriate cone factors for this soil type.
The aforementioned formula has been slightly modified and rephrased using the tip resistance values corrected for pore pressure effects $\left(q_{t}\right)$, as the use of CPTu tests became more common worldwide.

$$
s_{u}=\left(q_{t}-\sigma_{v 0}\right) / N_{k t}
$$

where $N_{k t}$ is the empirical cone factor (for the expression using $\left.q_{t}\right)$.

The use of pore pressure corrected tip resistance $\left(q_{t}\right)$ is especially important in the case of soft clays, where the measured pore pressure can be nearly as large as the measured tip resistance, thus the difference between $q_{c}$ and $q_{t}$ can be significant.

There are a vast number of studies available about values of $N_{k t}$ experienced in different geological conditions. Some of these experiences are summarized in Table 1

The $N_{k t}$ values, similarly to the $N_{k}$ values, vary over wide range, between 4 and 20. Some of the cited works have found that the cone factor is a function of certain soil parameters (e.g. plasticity index, overconsolidation ratio, pore pressure parameter), but later works did not confirm the presence of such relationships. Therefore it seems rather complicated to define a single soil property that governs the cone factors, probably because there are more factors affecting the $N_{k t}$ values.

Another possibility to calculate undrained shear strength from CPT tip resistance values is the use of effective cone resistance $q_{E}=q_{t}-u_{2}$.

$$
s_{u}=q_{E} / N_{k e}=\left(q_{t}-u_{2}\right) / N_{k e}
$$

where $N_{k e}$ is the empirical cone factor (for the expression using $\left.q_{E}\right)$.

The effective cone resistance has been successfully used also in other fields of geotechnics, such as soil classification (Fellenius, 1997) [4], pile capacity prediction (Mahler, 2007) [11], so it seems obvious to find a correlation between this value and the undrained shear strength. There are many proposals available for $N_{k e}$ values for different soil types. A brief overview of them is given in Table 2 .

In the case of soft clays the measured $q_{c}$ values are relatively small, so even minor errors can influence the measured values significantly. Therefore for very soft clays the use of excess pore water pressure may be better to find a reliable correlation:

$$
s_{u}=\Delta u / N_{\Delta u}=\left(u_{2}-u_{0}\right) / N_{\Delta u}
$$

where

$N_{\Delta u}$ is the empirical cone factor (for the expression using $\Delta u$ ), $u_{0}$ is the in-situ pore water pressure.

Lunne et al.[20] have found that the cone factors vary in this case between 4 and 10, Karlsrud et al. [21] experienced $N_{\Delta u}$ values between 6 and 8 . Recent experiences show similar values, ratios between 4 and 9 has been found by Hong et al. (2010) [6]. In addition, all author found that $N_{\Delta u}$ correlates well with the pore pressure ratio, $B_{q}$. This practically means that the cone 
Tab. 1. Recommendations for cone factor $N_{k t}$

\begin{tabular}{|c|c|c|c|}
\hline$N_{k t}$ value range & Reference test & Comments & Reference \\
\hline 8-16 & $\begin{array}{l}\text { triaxial compression, triaxial } \\
\text { extension and direct shear }\end{array}$ & $\begin{array}{c}\text { For clays }\left(3 \%<I_{p}<50 \%\right) N_{k t} \\
\text { increases with } I_{p}\end{array}$ & Aas et al. (1986) \\
\hline $11-18$ & & $\begin{array}{l}\text { Found no correlation between } \\
\qquad N_{k t} \text { and } I_{p}\end{array}$ & La Rochelle et al. (1988) \\
\hline $8-29$ & Triaxial compression & $N_{k t}$ varies with OCR & Rad and Lunne (1988) \\
\hline $10-20$ & Triaxial compression & & Powell and Quarterman (1988) \\
\hline $6-15$ & Triaxial compression & $N_{k t}$ decreases with $B_{q}$ & Karlsrud (1996) \\
\hline $7-20$ & Triaxial compression & $\begin{array}{l}\text { Busan clay, Korea } \\
25 \%<I_{p}<40 \%\end{array}$ & Hong et al. (2010) \\
\hline $4-16$ & Vane shear & $\begin{array}{l}\text { High plasticity, soft clay, } \\
42 \%<I_{p}<400 \%\end{array}$ & Almeida et al. (2010) \\
\hline
\end{tabular}

Tab. 2. Recommendations for cone factor $N_{k e}$

\begin{tabular}{cccc}
\hline$N_{k e}$ value range & Reference test & Comments & Reference \\
\hline $6-12$ & & For clays \\
$\left(3 \%<I_{p}<50 \%\right)$ & Senneset et al. (1982) \\
\hline $1-13$ & Triaxial compression & $N_{k t}$ decreases with $B_{q}$ & Karlsrud (1996) \\
\hline $3-10$ & Triaxial compression & $\begin{array}{c}\text { Busan clay, Korea } \\
25 \%<I_{p}<40 \%\end{array}$ & Hong et al. (2010) \\
\hline
\end{tabular}

factor can be predicted more accurately, which consequently results in better undrained shear strength prediction.

The soil samples used for this study were taken from 7 different sites along the highway M43 located in southern Hungary and another location in Hajdúszoboszló. At each site CPTu test were carried out in the vicinity of the drillhole. The undrained shear strength of 22 soil samples have been determined by means of consolidated-undrained (CU) triaxial compression tests and unconfined compression tests. The samples have been classified as silt and clay of varying plasticity. The undrained shear strength of the soils varied between 12 and 124 $\mathrm{kPa}$, thus the consistency of the soils could be defined as soft, firm and stiff. However, the characteristic CPT tip resistance values varied between 540 and $1900 \mathrm{kPa}$, which implies rather soft and firm soil conditions.

\section{Empirical cone factor values}

The aforementioned empirical cone factors were determined for each tested sample; the characteristic results are summarized in Table 3

The determined $N_{k}$ values vary typically between 10.5 and 27.6, having an average of 18.6. The typical values are in good agreement with the literature values, especially close to the German experiences (Gebreselassie, 2003) [5].

The cone factor values $N_{k t}$ and $N_{k e}$ have shown similar trends. The values vary over the same range described previously by other authors, but the mean seems to be slightly higher than experienced by others. This might be caused by the different nature and geological history of soils, but it can partially arise from the sampling quality as well. The scatter of the data is illustrated by Figure 1 , in addition to the measured values, the lines representing $N_{k t}=17, N_{k t}=32$ and the best fitting line are also plotted. The line of best fit has been determined by the method of least squares which minimizes the total deviation between predicted and measured values.

The cone factor values $N_{\Delta u}$ varied in a somewhat wider range than it was observed by other authors, and a more significant scatter can be observed. This is illustrated in Figure 2, here the best fitting line and the $N_{\Delta u}=17, N_{\Delta u}=32$ lines are also indicated. Nevertheless the mean value shows very good agreement with previously published results, so probably the difference experienced in the case of $N_{k}$ and $N_{k t}$ values are caused by the different geological formation of the soils rather than by sampling quality differences.

It seems worth to analyze whether there is a reliable correlation between the experienced $N_{\Delta u}$ values and the pore pressure coefficient $\left(B_{q}\right)$, as it was mentioned in previous works.

\section{Cone factor correlations}

Further investigations have been made in order to analyze if the cone factor could be estimated in a more reliable way as a function of another soil property. 
Tab. 3. Experienced cone factors

\begin{tabular}{ccccc}
\hline & $N_{k}$ & $N_{k t}$ & $N_{k e}$ & $N_{\Delta u}$ \\
\hline minimum value & 10.5 & 11.9 & 10.9 & 1.8 \\
\hline $\begin{array}{c}\text { arithmetic mean value } \\
\text { of the calculated cone factors }\end{array}$ & 18.6 & 23.3 & 18.3 & 6.3 \\
\hline maximum value & 27.6 & 32.1 & 28.6 & 13.1 \\
\hline
\end{tabular}

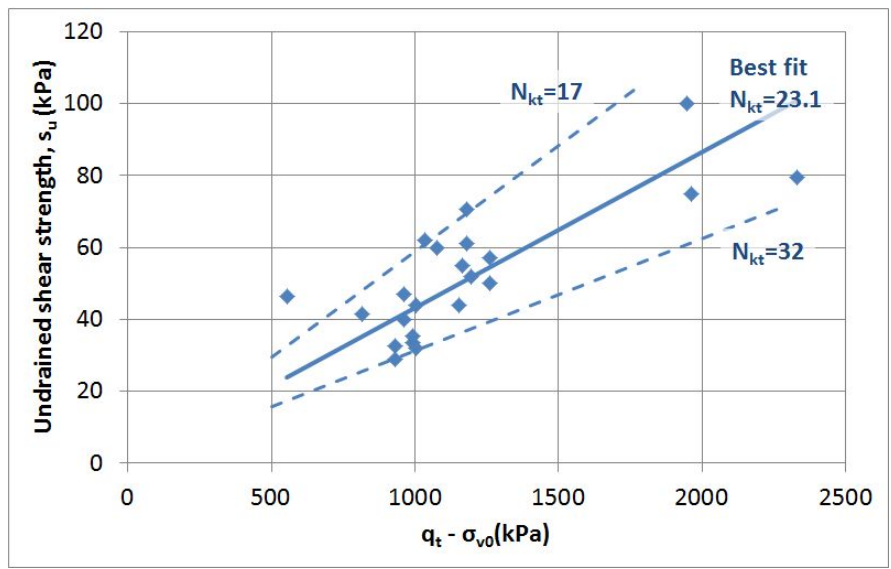

Fig. 1. CPT resistance vs. undrained shear strength

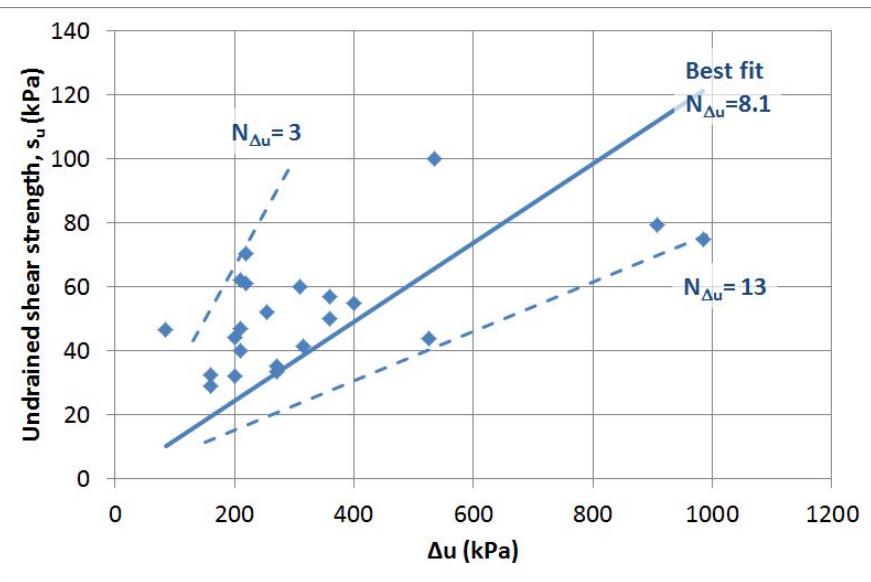

Fig. 2. CPT resistance vs. undrained shear strength

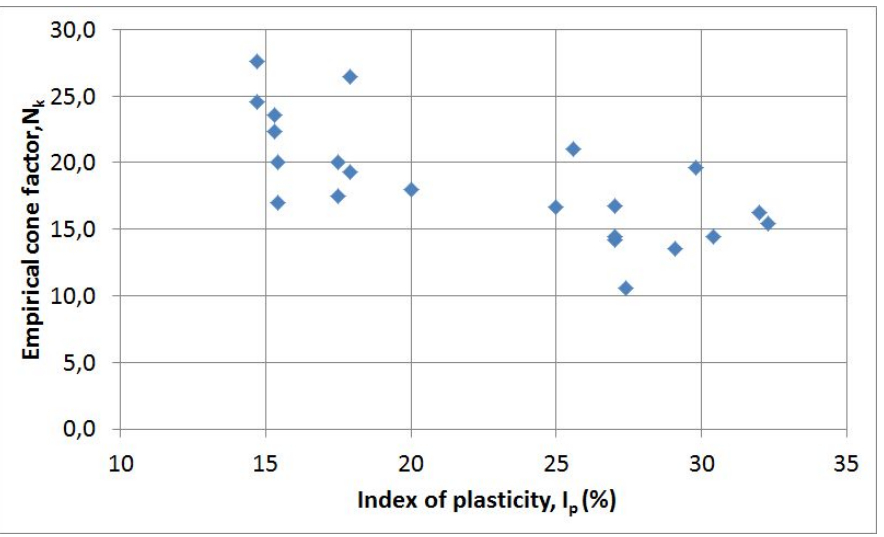

Fig. 3. Index of plasticity vs. Empirical cone factor $\left(N_{k t}\right)$
A widely used approach is to use higher cone factors for soils having higher $q_{c}$ values and lower ones for soils having lower CPT resistance. In our cases no such tendency can be observed, the correlation coefficients of undrained shear strength and the relevant CPT resistance $\left(q_{c}-\sigma_{0} ; q_{t}-\sigma_{0} ; q_{t}-u_{2} ; \Delta u\right)$ values are below 0.1 , indicating that not even weak correlation exists between these parameters.

Aas et al. (1986) [22] have found that the empirical cone factor depends on the plasticity index $\left(I_{p}\right)$ of soil, the larger the $I_{p}$, the larger the cone factor $\left(N_{k t}\right)$, but later works have not confirmed this tendency. The $N_{k t}$ values calculated for our samples have been plotted against the index of plasticity (Figure 3). It seems that, in contrary to the experiences of Aas et al. (1986)[22], $N_{k t}$ slightly decreases with increasing plasticity in the $I_{p}$ range of $14-33 \%$. It must be also noted that there is no strong correlation between the two parameters, the correlation coefficient is only $R^{2}=0.47$. In addition, $N_{k t}$ values for soils having nearly the same $I_{p}$ vary over a quite large range, for example they vary between about 20 and 40 in $I_{p}$ range of $15-20 \%$. This also implies a less reliable correlation.

For cone factors $N_{k}$ and $N_{k e}$ the trend and the correlation coefficients are very similar, so in contrary to a widely accepted belief, using an $I_{p}$ dependent empirical cone factor does not improve the reliability of undrained shear strength estimation significantly.

More authors have found that the empirical cone factor $N_{\Delta u}$ correlates well with the pore pressure coefficient $B_{q}$. By definition, this coefficient can be calculated by the following formula:

$$
B_{q}=\left(u_{2}-u_{0}\right) /\left(q_{t}-\sigma_{v 0}\right)
$$

where

$u_{2}$ is the pore pressure measured just behind the cone tip;

$u_{0}$ is the equilibrium pore pressure (consequently $u_{2}-u_{0}$ is the excess pore pressure, $\Delta u$ );

$\sigma_{\nu 0}$ is the total overburden stress.

Our calculated cone factor values have been plotted against the pore pressure coefficient $\left(B_{q}\right)$. In the case of $N_{k}, N_{k t}$ and $N_{k e}$ values no reliable correlation existed, but a better correlation was observed for $N_{\Delta u}$ (Figure 4): the correlation coefficient is $R^{2}=0.81$. The experienced cone factor values plot in a relatively narrow zone which can be defined by the following formula:

$$
N_{\Delta u}=\left(24.3 B_{q}\right) \pm 2
$$

The best fitting line, giving the most accurate prediction in average, can be expressed by the equation:

$$
N_{\Delta u}=24.3 B_{q}
$$

In low pore pressure coefficient range, the \pm 2 component of the expression (7). causes significant differences (e.g. the cone factor can vary between 2 and 6). This implies that care must be taken if using this correlation when the excess pore pressure is low. In the case of larger excess pore pressure its influence 
is much smaller, thus the undrained shear strength can be estimated in a more reliable way.

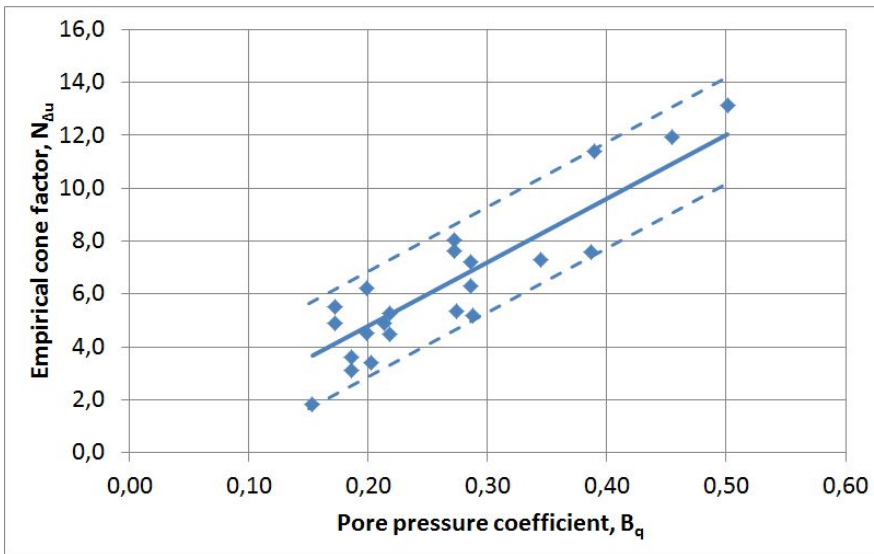

Fig. 4. Pore pressure coefficient $\left(B_{q}\right)$ vs. Empirical cone factor $\left(N_{\Delta u}\right)$

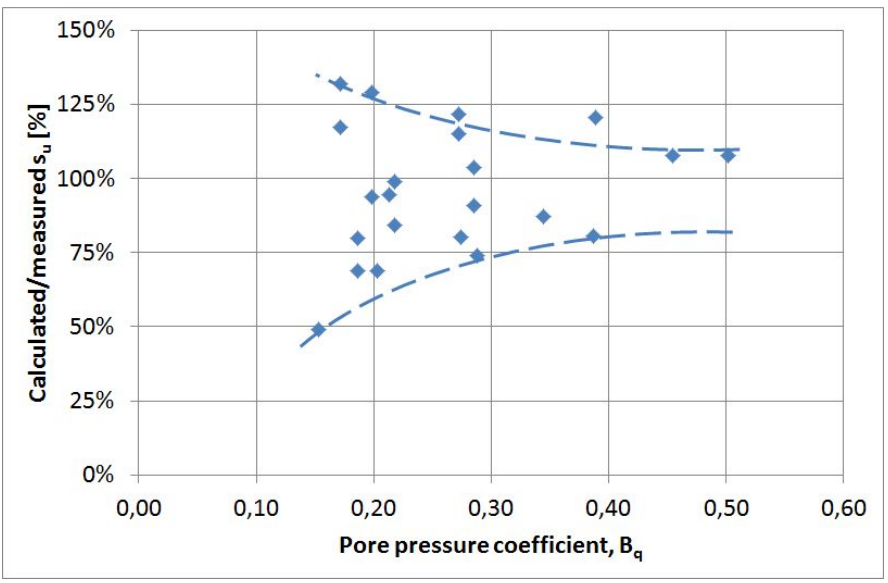

Fig. 5. Calculated/measured undrained shear strength as a function of $B_{q}$

This is also illustrated in Figure 5, the undrained shear strength was calculated by expression (8), and the ratio of calculated and measured $s_{u}$ was plotted against the pore pressure ratio $B_{q}$. The calculated undrained shear strength values vary over a range of $\pm 40 \%$, when the pore pressure ratio values are smaller than 0.25 . Thus in this case the reliability of the calculations is similar to that of the calculations using $N_{k}, N_{k t}$ and $N_{k e}$. Therewith the ratios of calculated and measured shear strength vary over a more narrow range $( \pm 25 \%)$ in case of $B_{q}>0.25$, so the in this case reliability of the calculation are better than that of any other calculation method. Generally, the low $B_{q}$ values are the characteristic or firm clays, and the increasing pore pressure coefficients implies more soft soil conditions or increasing sensitivity. Thus the proposed relationship provides more reliable results for soft clays.

\section{Conclusions}

The correlation of cone penetration resistance and undrained shear strength of Holocene clays has been discussed in the paper. There are many published correlations for different type of clays, but there is no experience about their reliability in case of Holocene clays in the Charpatian Basin. Based on CPT and laboratory test results of 22 samples it has been found that existing correlations overestimate the undrained shear strength of this clay, moreover the experienced cone factors $\left(N_{k}, N_{k t}, N_{k e}\right.$, $N_{\Delta u}$ ) vary over a significant range. The accuracy of the calculation is about $\pm 40 \%$, when cone factors $N_{k}, N_{k t}$, or $N_{k e}$, are used and even higher in case of $N_{\Delta u}$.

There are several studies that propose the use of a soil parameter (e.g. plasticity index, overconsolidation ratio, pore pressure coefficient of CPT) dependent cone factor to improve the accuracy of the calculations. In the case of $N_{k}, N_{k t}$, or $N_{k e}$, factors no such correlation has been observed, but a reliable correlation has been found between the cone factor $N_{\Delta u}$ and the CPTu pore pressure coefficient $B_{q}$.

Using a $B_{q}$ dependent $N_{\Delta u}$ cone factor increases the reliability of the calculation. In low $B_{q}$ range (i.e. in the case of firm clays) the calculated undrained shear strength values scattered over a range of $\pm 40 \%$, which is similar to the accuracy observed in the case of other cone factors, but in the cases of high $B_{q}$ values ( $B_{q}>0.25$, i.e. in the case of softer clays) the accuracy of the calculation is significantly better: about $\pm 20-25 \%$. So using the proposed formula (equation (8)) enables a more reliable undrained shear strength prediction for typical Holocene clays in the Charpatian Basin.

Such a calculation method provides a helpful guideline when there is no other data available about the undrained shear strength of the soil or when more information is needed to assess the uncertainty of the undrained shear strength of a certain layer. Thus it enables to have more realistic and more detailed information about the soil strength.

\section{References}

1 Almeida M, Marques M, Baroni M, Geotechnical parameters of very soft clays from CPTu, 2nd International Symposium on Cone Penetration Testing, CPT'10, In: Proceedings of 2nd International Symposium on Cone Penetration Testing, CPT'10, online, 2010. paper No. 2-46.

2 De Beer E, Static cone penetration testing in clay and loam, Sonder Symposium, In: Proceedings of Sonder Symposium, Fugro, 1977, pp. 15-23.

3 Chen C, Evaluating undrained shear strength of Klang clay from Cone penetration test, International Conference on In Situ Measurement of Soil Properties and Case Histories, In: Proceedings of the International Conference on In Situ Measurement of Soil Properties and Case Histories, Graduate Program, Parahyangan Catholic University, 2001, pp. 141-148.

4 Eslami A, Fellenius B, Pile capacity by direct CPT and CPTu methods applied to 102 case histories, Canadian Geotechnical Journal, 34, (1997), 880-898, DOI 10.1139/t97-056.

5 Gebreselassie B, Experimental, analytical and numerical investigations of excavations in normally consolidated soft soils, $\mathrm{PhD}$ thesis, University of Kassel, 2003.

6 Hong S, Lee M, Kim J, Lee W, Evaluation of undrained shear strength of Busan clay using CPT, 2nd International Symposium on Cone Penetration Testing, CPT'10, In: Proceedings of 2nd International Symposium on Cone Penetration Testing, CPT'10, online, 2010. paper No. 2-23.

7 Jörß O, Erfahrungen bei der Ermittlung von cu-Werten mit der Hilfe von Drucksondierungen in bindigen Böden, Geotechnik, 21, (1998), 26-27.

8 Ladanyi B, Deep punching of sensitive clays, 3rd Pan American Conference on Soil Mechanics and Foundation Engineering, In: Proceedings of the 3rd 
Pan American Conference on Soil Mechanics and Foundation Engineering, Sociedad Venezolana de Mecánica del Suelo e Ingeniería de Fundaciones, 1967, pp. 533-546.

9 Lunne T, Robertson P, Powell J, Cone penetration testing in geotechnical practice, Blackie Academic and Professional, Chapman and Hall, 1997.

10 Mahler A, Use of cone penetration test in pile design, Periodica Polytechnica - Civil Engineering, 47(2), (2003), 189-197, DOI 10.3311/pp.ci.20032.04 .

11 Mahler A, Settlement prediction of CFA piles based on CPTu results, 14th European Conference on Soil Mechanics and Geotechnical Engineering, In: Proceedings of the 14th European Conference on Soil Mechanics and Geotechnical Engineering, Millpress Science Publishers, 2007, pp. 359-364.

12 Mayne P, Coop M, Springman S, Huang A, Zornberg J, Geomaterial behavior and testing, 17th International Conference on Soil Mechanics and Geotechnical Engineering, In: Proceedings of the 17th International Conference on Soil Mechanics and Geotechnical Engineering, IOS Press / Millpress Science, 2009, pp. 2777-2872.

13 Nagy L, Hydraulic failure probability of a dike cross section, Periodica Polytechnica Civil Engineering, 52(2), (2008), 83-89, DOI 10.3311/pp.ci.2008-2.04.

14 Senneset K, Janbu N, Svano G, Strength and deformation parameters from cone penetration tests, 2nd European Symposium on Penetration Testing ESOPT-II, In: Proceedings of the 2nd European Symposium on Penetration Testing ESOPT-II, A A Balkema Publishers, 1982, pp. 863-870.

15 Skempton A, The bearing capacity of clays, Building Research Congress, In: Proceedings of the Building Research Congress, National Research Council, 1951, pp. 180-189.

16 Teh C, An analytical study of the cone penetration test, $\mathrm{PhD}$ thesis, Oxford University, 1987.

17 Terzaghi K, Theoretical Soil Mechanics, John Wiley and Sons, 1943.

18 Vesic A, Principles of pile foundation design, Duke University, Durham, NC., 1975.

19 Lunne T, Kleven A, Role of CPT in North Sea Foundation Engineering, In: Symposium on Cone Penetration Engineering Division, ASCE, 1981, pp. 49-75.

20 Lunne T, Christoffersen H, Tjelta T, Engineering use of piezocone data in North Sea clays, In: Proc. ICSMFE-11; San Francisco, 2, 1985, pp. 907912.

21 Karlsrud K, Lunne T, Brattlieu K, Improved CPTu correlations based on block samples, Nordisk Geoteknikermote; Reykjavik, 1996.

22 Aas G, Lacasse S, Lunne T, Hoeg K, Use of in situ tests for foundation design on clay, In: Procs. IN-SITU'86; Blacksburg, 1986, pp. 1-30. 